\title{
Trichome Density in Relation to Volatiles Emission and 1,8-Cineole Synthase Gene Expression in Thymus albicans Vegetative and Reproductive Organs
}

\author{
Natália T. Marques, ${ }^{* a}$ Alexandra Filipe, ${ }^{b}$ Patrícia Pinto, ${ }^{b}$ José Barroso, ${ }^{c}$ Helena Trindade, ${ }^{c}$ \\ Deborah M. Power, ${ }^{b}$ and Ana Cristina Figueiredo ${ }^{c}$ \\ ${ }^{a}$ Centro de Eletrónica, Optoeletrónica e Telecomunicações, Universidade do Algarve, Campus de Gambelas, \\ 8005-139 Faro, Portugal, e-mail: nmarques@ualg.pt

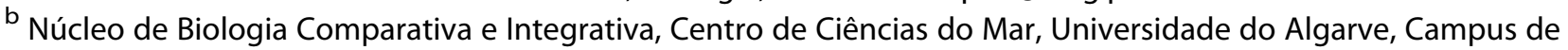 \\ Gambelas, 8005-139 Faro, Portugal \\ ' Centro de Estudos do Ambiente e do Mar (CESAM Lisboa), Faculdade de Ciências da Universidade de Lisboa, \\ Centro de Biotecnologia Vegetal (CBV), DBV, C2, Piso 1, Campo Grande, 1749-016 Lisboa, Portugal
}

1,8-Cineole is the main volatile produced by Thymus albicans HoffmanNs. \& LINK 1,8-cineole chemotype. To understand the contribution of distinct plant organs to the high 1,8-cineole production, trichome morphology and density, as well as emitted volatiles and transcriptional expression of the 1,8-cineole synthase (CIN) gene were determined separately for T. albicans leaves, bracts, calyx, corolla and inflorescences. Scanning electron microscopy (SEM) and stereoscope microscopy observations showed the highest peltate trichome density in leaves and bracts, significantly distinct from calyx and corolla. T. albicans volatiles were collected by solid phase micro extraction (SPME) and analyzed by gas chromatography-mass spectrometry (GC/MS) and by GC for component identification and quantification, respectively. Of the 23 components identified, 1,8-cineole was the dominant volatile (57-93\%) in all T. albicans plant organs. The relative amounts of emitted volatiles clearly separated vegetative from reproductive organs. Gene expression of CIN was assigned to all organs analyzed and was consistent with the relatively high emission of 1,8-cineole in leaves and bracts. Further studies will be required to analyze monoterpenoid biosynthesis by each type of glandular trichome.

Keywords: 1,8 -cineole, glandular trichomes, Lamiaceae, monoterpenes, SPME.

\section{Introduction}

Thymus albicans HOFFMANNS. \& LINK [= Origanum albicans (HoffmAnns. \& LINK) KUnTZE, Thymus mastichina var. micranthus Bolss., Thymus tomentosus var. virescens Coss., Thymus virescens (Coss.) PAU] is a perennial shrub native of the south Iberian Peninsula, and a member of the Lamiaceae, subfamily Nepetoideae and grows in pinewoods of Pinus pinea ${ }^{[1]}$ on the eastern coast of the Iberian Peninsula. T. albicans has an erect stem, flat leaves, lanceolate to obovate, inflorescence capituliform, white flowers protected by bracts and a very hairy calyx. Glandular trichomes are usually present on both the vegetative and reproductive organs of Lamiaceae species. $^{[2-4]}$ Glandular trichomes may differ in morphology and density between different plant organs or with the developmental stage of the organ ${ }^{[5]}$ or even in the same organ between the two blades. ${ }^{[6,7]}$ Glandular trichomes can produce, store and release plant secretions, which are a complex mixture of products of secondary metabolism such as monoterpenes, sesquiterpenes and/or phenylpropanoids. ${ }^{[8]}$ The production and chemical composition of plant secretions may vary qualitatively and quantitatively among plant organs and be dependent on their developmental stage. ${ }^{[5,9,10]}$ Several of the components of plant secretions that accumulate in the subcuticular space of glandular trichomes, namely monoterpenes and/or phenylpropanoids, are released into the atmosphere as volatiles. ${ }^{[8]}$ 
Isolation of volatiles using solid phase micro extraction (SPME)-based techniques has some advantages over essential oil (EO) isolation, including simple sample preparation, low solvent consumption, lowcost of extraction, rapid characterization of the main volatile components using low quantities of plant material, while preserving the original volatile composition. ${ }^{[11]}$

The volatile monoterpenes are generated through the action of monoterpene synthase (mTPS). mTPS transcript levels have been correlated with the volatile composition determined by EO analysis of leaf or flower extracts of Origanum vulgare and Lavandula latifolia, respectively. ${ }^{[12,13]} T$. albicans 1,8 -cineole chemotypes produce 1,8-cineole as the dominant constituent of EO. ${ }^{[14]}$ This oxygen-containing monoterpene is an antiseptic, analgesic, anticough, bronchodilator, myorelaxant and has immunostimulant activities and is of great interest for the pharmaceutical industry and medicine. ${ }^{[15,16]}$ The 1,8-cineole content in the chemotype may reach levels of up to $68 \% .{ }^{[17]}$ Glandular trichomes are involved in the production of this type of volatile compound. ${ }^{[2]}$ To date, studies of glandular trichome morphology and density in T. albicans are lacking.

Following a previous study where the 1,8-cineole enzyme (CIN) from $T$. albicans was heterologously expressed, ${ }^{[18]}$ the present study aimed to (1) characterize the morphology, distribution and density of peltate glandular trichomes in leaves, bracts, calyx and corolla of the T. albicans chemotype 1,8-cineole; (2) determine the SPME volatile profile of different plant organs and compare it with trichome density; and (3) determine the relative gene expression in different plant organs of CIN and compare it with the volatile profile.

\section{Results and Discussion}

\section{Types of Trichomes}

The indumentum of $T$. albicans contained non-glandular and glandular trichomes distributed over the vegetative and reproductive organs (Figures $1 a, 1 b, 2 a$, $2 b, 2 d$ and $2 f)$. Three types of glandular trichomes were identified: a) Type I: peltate trichomes, which consisted of a basal cell, a short monocellular stalk and
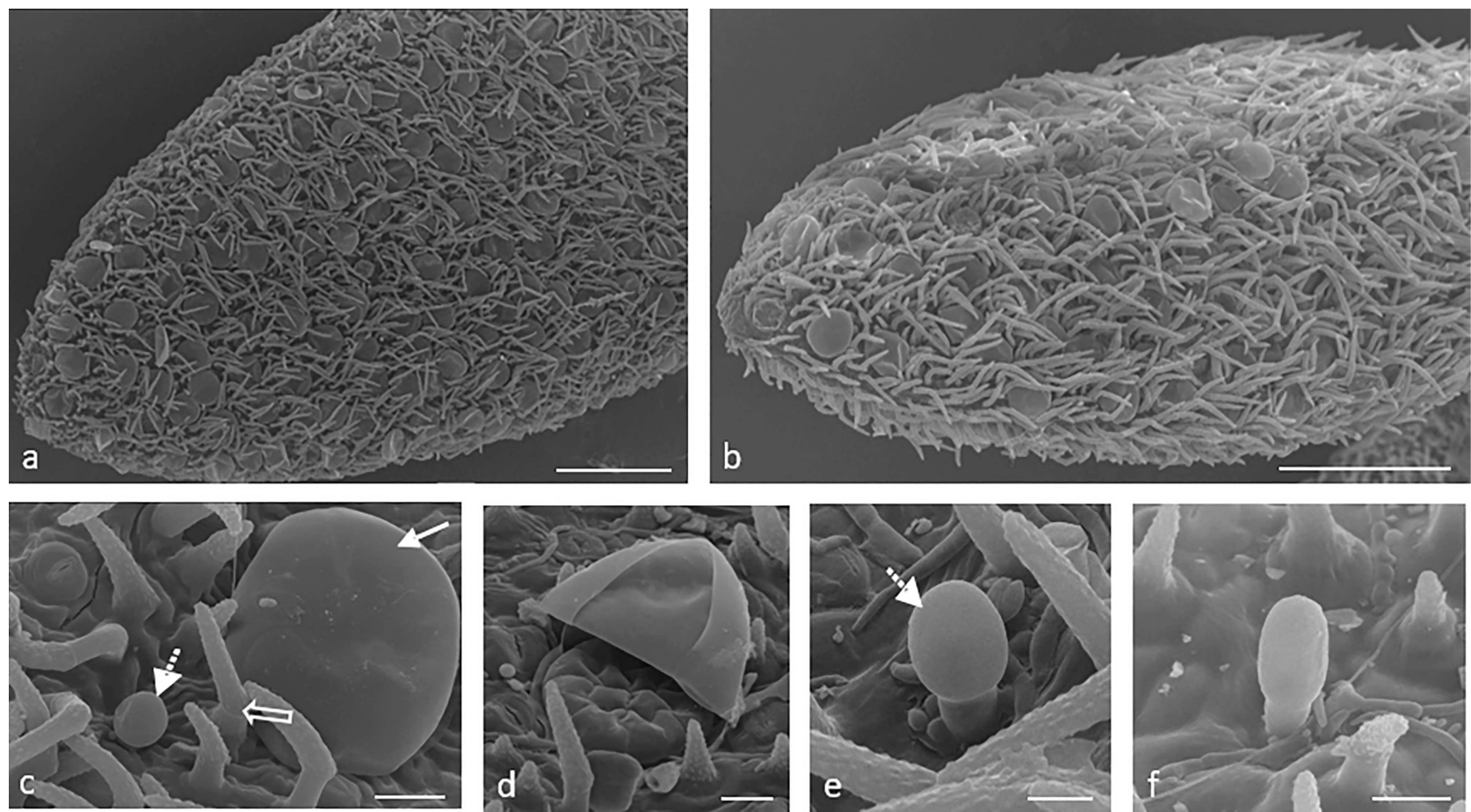

Figure 1. Scanning electron microscopy micrographs showing the distribution, density and types of trichomes on Thymus albicans leaves. a), b) Adaxial and abaxial leaf surfaces, respectively, of a portion of an apical leaf primordium showing the density of peltate and elongated non-glandular trichomes. c) A peltate trichome (type I trichome, arrowhead) and a capitate trichome (type II trichome, arrowhead with dotted line) on the abaxial side of the leaf in the middle of non-glandular trichomes (empty arrowhead). d) A trichome with a torn cuticular sheath disclosing the arrangement of the head cells in two circles. e), f) Capitate trichomes on the adaxial (arrowhead with dotted line) and abaxial surfaces of the leaf, respectively. Scale bars: $a$ ), $b$ ) $=300 \mu \mathrm{m} ; c)-f$ ) $=20 \mu \mathrm{m}$. 
a large secretory round head with 12 secretory cells (ca. $75 \pm 10 \mu \mathrm{m}$ in diameter) organized as four central cells surrounded by 8 cells in a single shield (Figure 1c and $1 d$ ). Type II: capitate trichomes composed of one stalk cell and a one-cell glandular head (ca. $14 \pm 3 \mu \mathrm{m}$ in diameter) (Figure 1e and 1f). Type III: digitiform trichome, with one or two stalk cells and an apical glandular cell with a diameter similar to the stalk cells (ca. $8 \pm 2 \mu \mathrm{m}$ in diameter) (Figure 2i). Non-glandular trichomes were uniseriate, of a bent point-shapedtype and formed by a variable number of cells (Figures $1 c$ and $2 c-2 e$ ), with the cells above the stalk cell displaying cuticular warts on the cell wall (Figures $1 c$ and $2 c$ ).

\section{Distribution and Density of Trichomes on Plant Organs}

Leaf. Leaves exhibited a dense tomentum of mixed peltate trichomes with non-glandular trichomes (Figure $1 a$ and $1 b$, Table 1). Capitate and digitiform trichomes (Figures 1e, $1 f$ and 2i) were scarce on both faces. Non-glandular trichomes had $2-3$ cells and were bent to the base of the leaves (Figure $1 a$ and $1 b$ ).

Bract. Peltate trichomes were dense on the abaxial face, while on the adaxial face they were clustered only at the apical lobe and were scarce on the two surrounding lobes (Figure 2a, Table 1). Capitate trichomes were scarce on the abaxial face (Figure $2 b$ ) and were predominant at the middle and base of the adaxial face where digitiform trichomes were scarce (Figure 2c, Table 1). Non-glandular trichomes were identified on the two faces and were composed of 23 cells (Figure $2 a-2 c$ ).

Calyx. On the abaxial face, peltate trichomes covered the tubular region but were scarce on the lobes (Figure 2d, Table 1). Type II and type III trichomes were rare and widely dispersed. On the inner face of the calyx, peltate and digitiform trichomes were very scarce and capitate trichomes predominated (Figure 2e, Table 1). In the upper tubular region, on the inner face, a dense villous indumentum constituted by erect non-glandular uniseriate and multicellular trichomes with 4-6 cells, were disposed in a ring
(Figure 2e). Long non-glandular trichomes, formed by 3-8 cells, bordered the lobes of the calyx and were disperse and randomly disposed along the tubular region, of the abaxial surface (Figure $2 d$ and $2 e$ ).

Calyx and bracts were much thinner than the leaves, with an estimated value of $0.014 \pm 0.002 \mathrm{~mm}$ for the calyx and $0.068 \pm 0.031-0.018 \pm 0.054 \mathrm{~mm}$ for the bract apex and medium/basal region. The estimated thickness of leaves was $0.132 \pm 0.031$. These differences can help explain the high CIN expression in the bracts (see below).

Corolla. Peltate trichomes were clustered mainly on the abaxial side and apical region of the corolla lobes (Figure 2f) and were absent from the inner tubular region (Table 1). Capitate and digitiform trichomes were very rare and were confined to the abaxial side of the corolla (Figure 2f). The upper surface of the ovarian lobes was covered in digitiform trichomes (Figure $2 g$ and $2 h$ ). Uniseriate non-glandular trichomes were dispersed on the abaxial surface and were sparse on the inner surface of the corolla (Figure $2 f$ and $2 g$ ).

The variability in coverage and relative proportion of glandular trichomes to non-glandular trichomes on the two sides of the blade of each organ in T. albicans was comparable with other thyme species. ${ }^{[3,19]}$ Digitiform trichomes, typically rare on all plant organs, were numerous and unique to the apical surface of the ovarian lobes (Figure 2i). Digitiform trichomes have been described in several Portuguese Thymus species, including the leaves of $T$. caespititius, ${ }^{[4]}$ and the leaves and calyx of T. mastichina. ${ }^{[20]}$

Scanning electron microscopy images suggested that peltate trichomes accumulated secretion above the glandular cells in the subcuticular space and that this conferred the spherical shape, characteristic of mature peltate glands (Figure 1c). Cuticular rupture of peltate trichomes in $T$. albicans followed a fragility line on the medium region of the glandular head (Figure $1 d$ ) and provided the means for secretion release. A similar type of rupture in peltate trichomes of other Thymus species has been reported. ${ }^{[19]}$

Peltate trichome density was higher in leaves and bracts, followed by sepals and flowers (Figure $1 a$ and

Table 1. Glandular trichome distribution and abundance in distinct plant organs of six Thymus albicans HoFFMANNS. \& LiNK plants.

\begin{tabular}{|c|c|c|c|c|c|c|c|c|}
\hline \multirow[b]{2}{*}{ Plant organ } & \multicolumn{8}{|c|}{ Glandular trichome distribution } \\
\hline & Leaf & & Bract & & Calyx & & Corolla & \\
\hline Trichome type & Adaxial & Abaxial & Adaxial & Abaxial & Adaxial & Abaxial & Adaxial & Abaxial \\
\hline Capitate & Scarce & Scarce & Abundant & Scarce & Abundant & Scarce & Absent & scarce \\
\hline Digitiform & Scarce & Scarce & Scarce & Scarce & Scarce & Scarce & Absent & Scarce \\
\hline
\end{tabular}



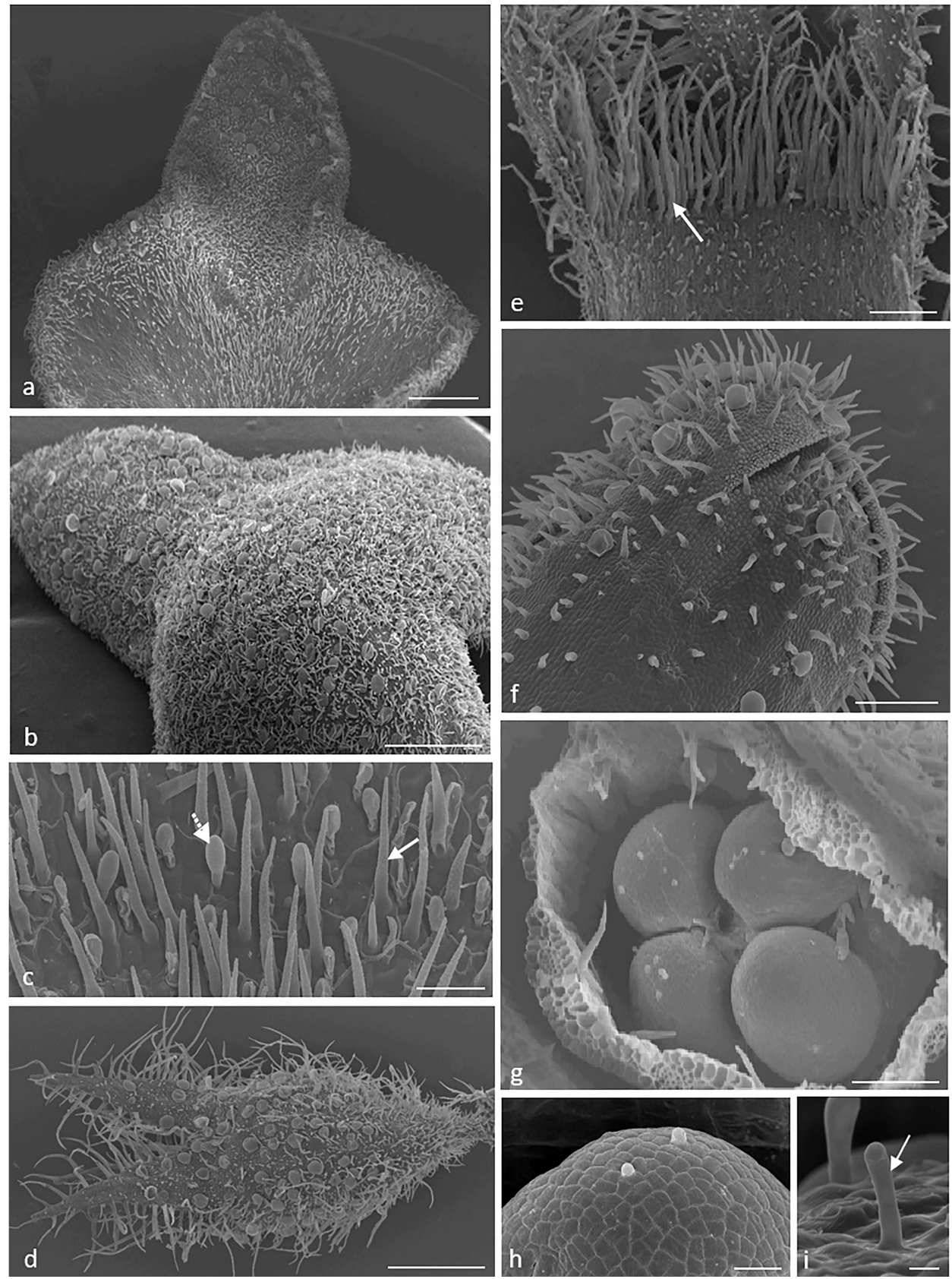

Figure 2. SEM (Scanning Electron Microscopy) micrographs showing the distribution, density and type of trichomes on Thymus albicans flower organs. a) -c) The adaxial and abaxial faces of a full-developed bract primordium: a) shows the distribution of peltate trichomes on the adaxial face, concentrated at the apical lobe, and of capitate trichomes at the center of the bract and distal lobes. b) Distribution of peltate trichomes on the abaxial face of a bract. c) Capitate trichomes (arrowhead with dotted line) are common at the center and distal lobes of the bracts and are interspersed with non-glandular trichomes (arrowhead). d),e) Trichome distribution on the abaxial and adaxial face, respectively, of a calyx primordium. d) A general view of the abaxial face of a calyx primordium showing the density of peltate and non-glandular trichomes distributed in the tubular and lobe regions. e) The adaxial face of the calyx has a tuft of non-glandular trichomes disposed in a ring at the base of the lobes (arrowhead). Below the dense indumentum only capitate trichomes are present. f)-i) Distribution and type of trichomes on the corolla. $f$ ) An early ontogenic stage of a flower with peltate and non-glandular hairs on the abaxial face of the corolla. g) General view of a developed ovary from a young flower, showing scarce digitiform trichomes on the top surface of the ovary lobes. $h$ ) An early ontogenic stage of digitiform trichomes on the surface of the ovarial lobe. i) Digitiform trichome (Type III trichome) (arrowhead) on the adaxial face of the calyx. Scale bars: a),b),d) $=500 \mu \mathrm{m} ; \mathrm{c})=50 \mu \mathrm{m} ; \mathrm{e}), \mathrm{f})=200 \mu \mathrm{m} ; \mathrm{g})=100 \mu \mathrm{m} ; \mathrm{h})=20 \mu \mathrm{m} ; \mathrm{i})=10 \mu \mathrm{m}$. 
$1 b$, Table 2). There were significant differences in the trichome density among the four plant organs (Kruskal-Wallis test; $\chi^{2}=40.18 ; \mathrm{df}=3 ; \mathrm{P}=0.00$ ), between the leaves and the corolla or calyx, between the bracts and the corolla and even between the corolla and the calyx (Mann-Whitney U-test, $p=0$ for all cases). Trichome density was significantly different between the abaxial and adaxial faces of major plant organs (Kruskal-Wallis test; $\chi^{2}=59.108 ; \mathrm{df}=5 ; \mathrm{P}=$ $0.00)$. There were no significant differences in trichome density between the adaxial and abaxial face of leaves (Mann-Whitney U-test, $p=0.6$ ) and between these with abaxial face of bracts (Mann-Whitney U-test, $p=$ 0.6 and $p=0.4$, respectively). All the other possible pairwise comparisons revealed significant differences in trichome density (Mann-Whitney U-test, $p=0$ for all cases) (Table 2). No peltate trichomes were found on the adaxial faces of the corolla and the calyx, so Kruskal-Wallis test and pairwise Mann-Whitney U-test were not performed for these plant parts.

A similar distribution of peltate trichomes in both faces of leaves was also reported for several Mentha species. $^{[21]}$ A distinct pattern was found in Thymus vulgaris with a high peltate density (around 2-fold higher) for leaves on its adaxial face ${ }^{[5]}$ thus indicating that trichome density is species and plant organspecific.

High peltate trichome density probably plays a defensive role against biotic agents and, along with non-glandular trichomes, contributes to shelter the plant from damaging radiation and high temperatures. ${ }^{[22-24]}$ In fact, these plants live in dry and consolidated sandy soils under high light intensity and the dense layer of peltate trichomes may provide better protection by reflecting sunlight and thus minimizing water loss, as proposed by Tozin et al. ${ }^{[25]}$

Due to the high density of non-glandular trichomes in developed leaves and bracts, it was not possible to count accurately small capitate and digitiform tri-

Table 2. Peltate trichome density $/ \mathrm{mm}^{2}$ in distinct vegetative and reproductive organs of six Thymus albicans HoffMANNs. \& LINK plants. ${ }^{[a]}$

\begin{tabular}{|c|c|c|c|c|}
\hline \multirow[b]{2}{*}{ Plant organ surface } & \multicolumn{4}{|c|}{ Peltate trichome density $/ \mathrm{mm}^{2}$} \\
\hline & Leaf & Bract & Calyx & Corolla \\
\hline dax & $66 \pm$ & $26 \pm$ & - & - \\
\hline Abax & & & $37 \pm 8^{c}$ & $4 \pm 1^{d}$ \\
\hline \multicolumn{5}{|c|}{$\begin{array}{l}\text { [a] Values are presented as mean } \pm \text { SD followed by letters. } \\
\text { Different letters indicate statistically significant differences in } \\
\text { trichome density among the adaxial and abaxial faces of plant } \\
\text { organs (Mann-Whitney U-test, } P<0.05 \text { ). }\end{array}$} \\
\hline
\end{tabular}

chomes. Of all the organs studied in T. albicans, the corolla had the lowest glandular trichome density (Table 2).

Volatiles Emitted by T. albicans Leaves and Floral Organs

To evaluate the volatiles emitted by different aerial organs of $T$. albicans, each plant part was assessed separately. The inflorescence was assessed with two leaves (Figure 1). Due to the low levels of volatiles emitted by one corolla, clusters of 10 were analyzed. Volatiles, collected by SPME from the inflorescence and leaves, leaves, the bract, the calyx and 10 corollas, are depicted in Table 3 in order of their elution on a DB-1 column. The isolated volatiles were a complex mixture, and 23 components representing $\geq 94 \%$ of the total volatiles were identified. The monoterpene fraction was dominant in all samples analyzed (86$98 \%$ ), while the sesquiterpene fraction ranged from trace levels to $15 \%$. The relative amount of oxygencontaining monoterpenes (74-96\%) was higher than that of monoterpene hydrocarbons (1-5\%). 1,8Cineole was the dominant emitted volatile (57-93\%) from all assayed $T$. albicans plant organs, followed by another oxygen-containing monoterpene, $\alpha$-terpineol $(0.2-17 \%)$, and the sesquiterpene hydrocarbon, $\beta$ elemene (traces $-9 \%$ ).

1,8-Cineole attained the highest relative amount in the leaf volatiles, but the inflorescence, the bracts, the calyx and the corolla also had high percentages of 1,8cineole (Table 3). Despite the similar volatiles profile, quantitative differences distinguished the vegetative and reproductive organs. Several compounds that were present in trace amounts in the leaf attained appreciable amounts in the corolla volatiles (Table 3), even though this organ had a low density of all types of trichomes. A similar result was found for leaves and flowers of T. mongolicus. ${ }^{[26]}$

Previous studies of EO analysis and yield related the type and density of glandular trichomes with the quality and quantity of compounds produced. In Mentha $\times$ piperita, the density of glandular trichomes in leaves was correlated with the essential oil yield. ${ }^{[27]}$ In Schizonepeta tenuifolia and in Menthaxpiperita, monoterpenoid volatiles were produced within peltate trichomes. ${ }^{[28,29]}$

The relatively high percentage of 1,8-cineole emitted by 10 corollas, each of which had a higher number of peltate trichomes on their abaxial surface compared to capitate trichomes (Figure 2f), suggests that peltate trichomes may be the main site of 
Table 3. Percentage composition of the SPME volatiles isolated from the different aerial parts of Thymus albicans collected in the Campus of the Universidade do Algarve, Faro, Portugal.

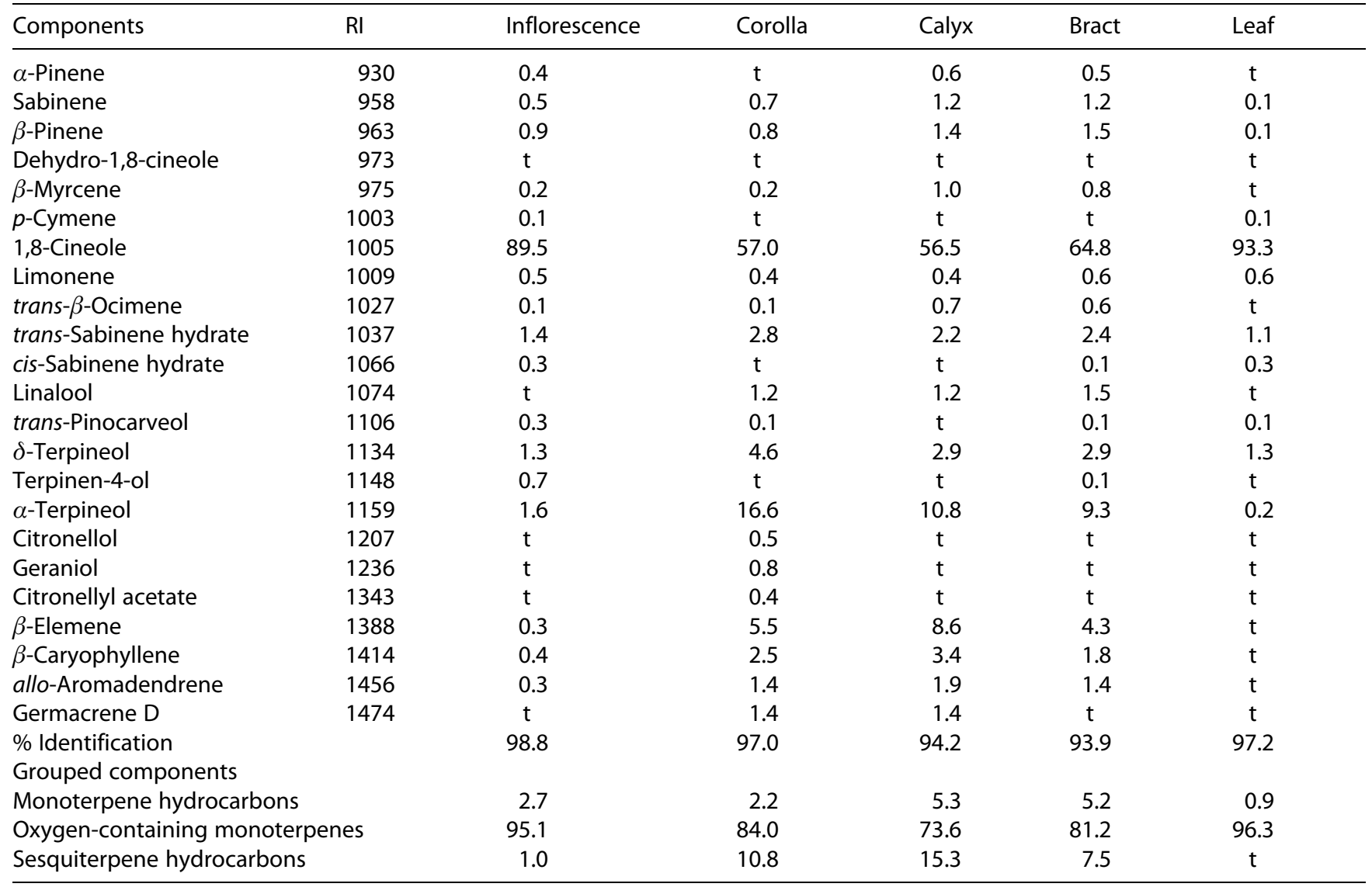

${ }^{[a]}$ RI: In-lab calculated retention index relative to $C_{9}-C_{15} n$-alkanes on the DB-1 column, t: traces $(<0.05 \%)$.

production of 1,8-cineole in $T$. albicans. Further support comes from the observation that there is a high density of peltate trichomes on leaves and bracts (Figures $1 a, 1 b$ and $2 b$; Table 2 ), where a relatively high percentage of 1,8-cineole was detected (Figure 3).

A number of studies have evaluated $T$. albicans EO composition. 1,8-Cineole was the main component in EOs isolated from the leaf (65\%) and inflorescences $(59 \%) .{ }^{[14]}$ Nevertheless, no previous studies have determined $T$. albicans headspace volatiles.

Gene Expression of 1,8-Cineole Synthase in T. albicans Leaves and Floral Organs

CIN is a multi-product enzyme that synthesizes several monoterpenes, called the 'cineole cassette', which include $\alpha$-terpineol, 1,8-cineole, $\alpha$-pinene, $\beta$-pinene, limonene, myrcene and sabinene, ${ }^{[30]}$ and is present in Salvia officinalis ${ }^{[31]}$ and Lavandula $\times$ intermedia. ${ }^{[13]}$ The multi-product enzyme CIN from $T$. albicans is involved in the synthesis of $\alpha$-pinene, $\beta$-pinene, $\beta$-myrcene and sabinene in addition to 1,8 -cineole. ${ }^{[18]}$

In the present study, the abundance of CIN transcripts was evaluated in leaves, bracts, calyx and perianth (composed of the calyx and the corolla) and compared to the relative amounts of volatiles emitted. $\mathrm{CIN}$ transcripts were identified and were differentially expressed in all analyzed organs of T. albicans (Figure 3). CIN transcripts were higher in the leaves, bracts and perianth relative to the calyx. Since CIN was highly expressed in the perianth relative to the calyx, it may be concluded that the corolla also expressed CIN (Figure 3). Bracts have fewer trichomes compared to the leaves (Table 2), however, they exhibited high CIN gene expression (Figure 3 ), a result sustained by the low organ thickness, while the amount of total RNA analyzed by qRT-PCR was the same for both. The differing thickness of plant organs may also explain the high values of CIN gene expression for the calyx and perianth compared to the leaves. 


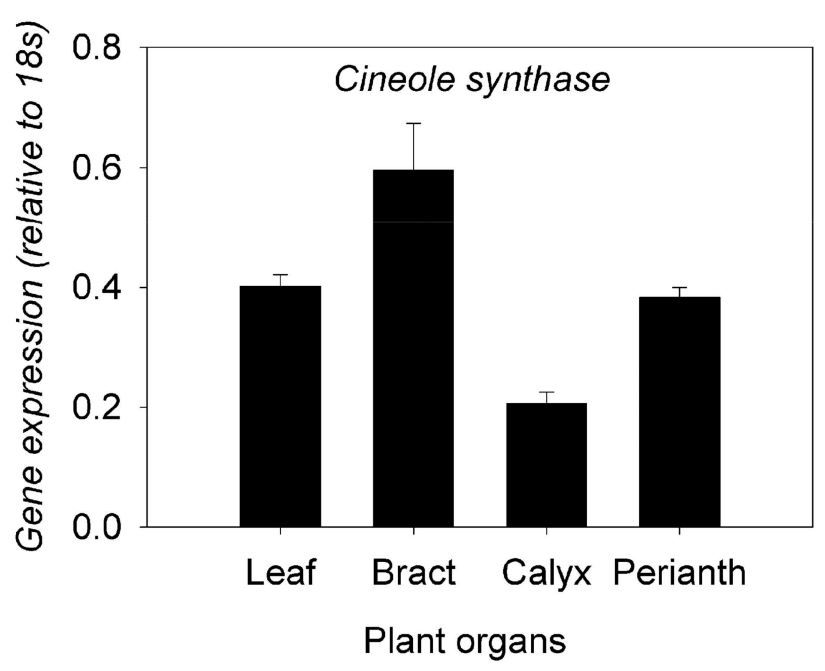

Figure 3. Relative $\mathrm{qPCR}$ (quantitative polymerase chain reaction) quantification of 1,8 -cineole synthase in young plant organs including leaves, bracts, calyx and perianth collected from an individual plant of Thymus albicans. Columns represent the mean expression value and standard deviation obtained from three technical replicates and two independent assays. Transcript levels were normalized using as the internal control $18 \mathrm{~S}$.

A correspondence between the EO composition and the abundance of mTPS transcripts has previously been reported indicating that mTPS activity is predominantly regulated at the level of transcription. ${ }^{[12,13,32]}$

Considering that CIN is a multiproduct enzyme in $T$. albicans, ${ }^{[18]}$ the content of volatiles assigned to the 'cineole cassette' was compared among the plant organs and with the relative levels of CIN transcripts. Most volatiles isolated from leaves and bracts were quantitatively and qualitatively dissimilar, moreover, the high transcript level of CIN was not coherent with production of compounds of the 'cineole cassette' given that leaves emitted relatively low or trace amounts of them. In contrast, bracts and calyces had a similar richness of volatiles in quantitative and qualitative terms, but dissimilar amounts of the CIN transcripts.

The abundance of peltate trichomes compared to capitate trichomes points to their important contribution to the essential oil yield in T. albicans. Studies in Schizonepeta tenuifolia showed that capitate and digitiform glandular trichomes may not contain significant levels of terpenoid volatiles. ${ }^{[29]}$ Further studies are needed to analyze monoterpenoid biosynthesis by each type of $T$. albicans glandular trichome.

\section{Conclusions}

T. albicans HoffmAnNS. \& LINK 1,8-cineole chemotype produces 1,8-cineole, a compound highly valued by industry. In the present study, 1,8-cineole was the dominant volatile isolated by SPME from the inflorescences, corolla, calyx, bracts and leaf of this species. The emitted volatile compounds and their relative amounts clearly separated the vegetative and reproductive organs. Leaves were the organs that emitted higher relative amounts of 1,8-cineole, followed by the bract and the calyx. The density of glandular peltate trichomes was significantly different $(P<0.05)$ between plant organs and varied between the adaxial and abaxial faces except for leaves. Gene expression of CIN was assigned to all organs analyzed and relative expression levels were consistent with the high emission by leaves and bracts of 1,8-cineole. Assessing the relative contribution of the multi-product CIN to the synthesis of a 'cineole cassette' among the plant organs studied was not straightforward and further work is needed to determine the specific activity and regulatory mechanisms of this enzyme among plant organs and assigned to each type of glandular trichome. Additional studies on the compounds emitted by each trichome will also be required to analyze its monoterpenoid biosynthesis.

\section{Experimental Section}

\section{Plant Material}

T. albicans HoffmAnNs. \& LINK 1,8-cineole chemotype was collected from a wild grown population, distributed around $10 \mathrm{~m}^{2}$, in the Campus of the Universidade do Algarve (Faro, Portugal), during May of 2017. Fully blooming aerial parts of $T$. albicans were always collected early in the morning, and each inflorescence consisted mostly of recently opened flowers. Voucher specimen (No. 15740/ALGU), identified by Manuela David (Herbarium curator) and Natália Marques, was deposited in the Herbarium Collection of Faculty of Sciences, Universidade do Algarve (Faro, Portugal).

\section{Scanning Electron Microscopy}

Samples of young and differentiated leaves, collected immediately below the inflorescence, bracts, calyx, and corolla, were prepared for scanning electron microscopy according to Figueiredo and Pais. ${ }^{[33]}$ Plant organs were fixed in $1.5 \%$ glutaraldehyde in $0.05 \mathrm{M}$ sodium cacodylate buffer, $\mathrm{pH} 7.0$, for $45 \mathrm{~min}$ at room 
temperature. After washing the fixed material in the same buffer, an additional fixation step was performed in $3 \%(\mathrm{v} / \mathrm{v})$ glutaraldehyde in $0.1 \mathrm{M}$ sodium cacodylate buffer, $\mathrm{pH}$ 7.0, for $2 \mathrm{~h}$ at room temperature. After fixation the samples were rinsed in the buffer, then dehydrated in a graded ethanol series (10\% to $100 \%$ ethanol) and critical point dried in a Polaron E 3500. Dried specimens were mounted on stubs and coated with gold in a Polaron E 5350. Observations were carried out using a JEOL T220 scanning electron microscope (JEOL Ltd., Tokyo, Japan) at an accelerating voltage of $15 \mathrm{kV}$.

\section{Trichome Density}

The number of cells forming each trichome were determined using images from SEM (Scanning Electron Microscopy) and from optical microscopy (OM) (not shown). To estimate the peltate trichome density in leaves, bracts, calyx and flowers, in both adaxial and abaxial surfaces, developed plant organs were randomly selected from six plants. Six samples from each plant part were evaluated, from all plants. Leaves were sampled immediately below the inflorescence. Plant organs were photographed under a stereoscope (Zeiss Stemi 508 Stereo Microscope). SEM images of fully developed organs were used, when necessary, to complement the counts per $\mathrm{mm}^{2}$ of trichomes estimated with the stereoscope (images not shown). Peltate trichome density was calculated using ImageJ software $^{[34]}$ and expressed as the mean value \pm standard deviation (SD) of counts per $\mathrm{mm}^{2}$. The small size of capitate and digitiform trichomes and high density of non-glandular trichomes in leaves and bracts, impaired the correct counting of these trichomes. Plant organ's thickness was estimated to understand attained values of CIN gene expression for leaves and bracts (see below Real-time qPCR). Leaves, bracts and sepals were cut transversally and thickness of plant organs near the midvein determined using images from a stereoscope and from SEM. Statistical analysis was performed using the non-parametric Kruskal-Wallis test followed by pairwise post-hoc comparisons performed with the Mann-Whitney's Utest. Statistically significant differences between the groups analyzed was assumed when $P<0.05$, using the IBM SPSS statistics software version 26 .
Sampling of Volatiles by Solid Phase Microextraction (SPME)

Volatiles from young and differentiated leaves, collected immediately below the inflorescence, the inflorescences, as well as individual corollas, calyx and bracts, were sampled by SPME on the same day they were collected. Volatiles were collected on two different days from two different plants, and in total four independent SPME experiments were performed per plant part. With the exception of corollas, which were analyzed in clusters of ten, all other plant parts were assessed individually (Figure 4). For collection of volatiles, the plant organs were inserted into $10 \mathrm{~mL}$ clear vials, sealed with a screw top solid cap containing a polytetrafluoroethylene (PTFE) liner.

Headspace volatiles were collected by SPME using $100 \mu \mathrm{M}$ polydimethylsiloxane (PDMS) coated fibers (Supelco, USA) inserted into manually operated SPME holders. Each holder needle was inserted through the PTFE liner and extraction using the coated fiber was achieved by holding it for $30 \mathrm{~min}$ at room temperature. Each SPME fiber was thermally conditioned for up to $25 \mathrm{~min}$ at $250^{\circ} \mathrm{C}$ before use, according to the manufacturer recommendations. Blank experiments using fibers in empty vials were carried out regularly.

\section{SPME Chemical Analysis}

Plant volatiles isolated by SPME were analyzed by gas chromatography-mass spectrometry (GC/MS) for com-

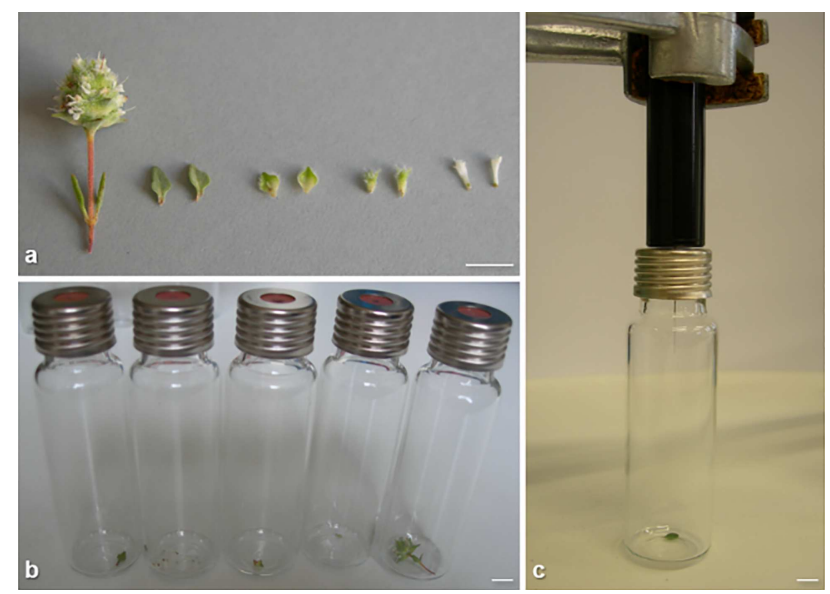

Figure 4. Detail of the Thymus albicans plant parts used in the experiment, namely inflorescence, leaves, bracts, calyx and corolla (a), showing the plant parts inside the vials (b) and of SPME volatile collection of an individual leaf (c). $B a r=0.5 \mathrm{~cm}$. 
ponent identification and by gas chromatography (GC) for component quantification.

\section{Gas Chromatography (GC)}

Immediately after sampling, the SPME needle was introduced into the split/splitless injector of a Clarus 400 gas chromatograph equipped with two flame ionization detectors, with a data handling system and a vaporizing injector port into which two columns of different polarities were inserted: a DB-1 fused-silica gel column $(100 \%$ dimethylpolysiloxane, $30 \mathrm{~m} \times$ $0.25 \mathrm{~mm}$ i.d., film thickness $0.25 \mu \mathrm{m}$; J \& W Scientific Inc., CA, USA) and a DB-17HT fused-silica gel column [(50\%-phenyl)methylpolysiloxane, $30 \mathrm{~m} \times 0.25 \mathrm{~mm}$ i.d., film thickness $0.15 \mu \mathrm{m}$; J \& W Scientific Inc., CA, USA]. The oven temperature was programmed from 45 to $175^{\circ} \mathrm{C}$, at $3^{\circ} \mathrm{C} / \mathrm{min}$, then, up to $300^{\circ} \mathrm{C}$ at $15^{\circ} \mathrm{C} / \mathrm{min}$, and finally held isothermal for $10 \mathrm{~min}$, for a total run time of $61.67 \mathrm{~min}$. The analyte desorption was achieved in splitless mode for $1 \mathrm{~min}$, and the gas chromatographic settings were as follows: injector and detector temperatures were $250^{\circ} \mathrm{C}$ and $290^{\circ} \mathrm{C}$, respectively; carrier gas was $\mathrm{H}_{2}$ at $30 \mathrm{~cm} / \mathrm{s}$. The percentage composition of the volatiles was computed by the normalization method from the GC peak areas without the use of correction factors. The values shown represent the mean value of four injections.

\section{Gas Chromatography Mass Spectrometry (GC/MS)}

GC/MS analysis was performed according to Filipe et al. ${ }^{[18]}$ The identity of the components was assigned by comparing their retention indices (RI) to $C_{8}-C_{15} n$ alkane indices, and GC/MS spectra from a laboratorymade library built based upon the analyses of reference essential oils, laboratory-synthesized components, and commercially available standards.

\section{RNA Extraction and cDNA Synthesis}

Samples consisted of young leaves, bracts, calyx and perianth (corolla plus calyx), collected during May 2017. The material was weighed and immediately frozen at $-80^{\circ} \mathrm{C}$. Given the difficulty in separating individual corollas for high quality RNA isolation, both individual calyx and perianth were analyzed, which allowed indirect determination of corolla gene expression. Tissues (100 mg each) were ground in liquid nitrogen with a pestle and mortar, and the total cellular RNA (tRNA) extracted using TriReagent ${ }^{\circledR}$ Solution $\left(\right.$ Ambion $^{\circledast}$ ) according to the manufacturer's instructions. tRNA quality and concentration was evaluated using a NanoDrop1000 spectrophotometer (Thermo Scientific). For cDNA synthesis, $250 \mathrm{ng}$ of total RNA was reverse transcribed using M-MLV reverse transcriptase (Promega), according to the manufacturer's instructions.

\section{Real-Time Quantitative PCR ( $q P C R)$}

qPCR (quantitative polymerase chain reaction) was performed to amplify the 1,8-cineole synthase (CIN) gene in $T$. albicans cDNAs of different plant organs. The CIN gene sequence ${ }^{[18]}$ was used to design the primer pairs and their specificity was confirmed by searching against the $\mathrm{NCBI}$ databases using the Primer-BLAST analysis tool (https://www.ncbi.nlm.nih.gov/tools/primer-blast/).

Expression analysis of 1,8-cineole synthase transcripts was performed by qPCR in a Bio-Rad iCycler iQ5 thermocycler (BioRad, USA) using the relative standard curve method. $18 \mathrm{~S}$ was used as the reference gene to normalize cDNA quantity. The $\mathrm{qPCR}$ reaction mixture was previously described. ${ }^{[35]}$ Primer pairs for amplification of the CIN gene were Cin29 Fw 5'-GATTAGGCAAGTGAAGATG-3' and Cin20 Rv 5'-GTCGTGATGAAACAAATGA-3', and for amplification of the control gene 18S, Fw 5'-GACTACGTCCCTGCCCTTTG-3' and Rv 5'CGCGATCCGAACATTCACC-3'. All qPCR reactions were performed in duplicate in three independent assays. Each qPCR experiment included a non-template control and a control with CDNA synthesized without reverse transcriptase. The thermal cycling for $\mathrm{qPCR}$ amplifications was $95^{\circ} \mathrm{C}$ for $10 \mathrm{~min}$, followed by 45 cycles of $95^{\circ} \mathrm{C}$ for $30 \mathrm{~s}$, and $52^{\circ} \mathrm{C}$ for $20 \mathrm{~s}$, with a final elongation step at $72^{\circ} \mathrm{C}$ for $30 \mathrm{~s}$. A melting curve between $65^{\circ} \mathrm{C}$ and $95^{\circ} \mathrm{C}$ after template amplification was used to confirm primer specificity and the amplified products were sequenced to check the specificity of the qPCR. Both pairs of primers used in the study had amplification efficiencies equal to or above $98.9 \%$ with regression coefficients $\left(R^{2}\right)$ of the standard curves $>0.99$.

A standard curve was prepared for the 1,8-cineole synthase amplicon and 18S, from purified plasmids containing these sequences, so that the amplification cycle could be related to the initial template quantity, determined using a nanodrop. Copy number determination of the CIN mRNA and 185 was done according to Afonso et al. ${ }^{[35]}$ Relative expression of 1,8-cineole synthase levels in each plant organ was estimated 
using the ratio between its copy number and the calculated copy number of the internal control $18 \mathrm{~S}$. Mean values of relative expression for each plant organ were calculated based on duplicate measurements.

Statistical analysis was performed using one-way ANOVA followed by a Tukey test, using SigmaStat v.3.50 (Systat Software, USA). Kruskal-Wallis ANOVA on ranks was used when normality conditions were not met.

\section{Acknowledgements}

Alexandra Filipe was funded by Ceratonia Project MONOTHYMUS, Universidade do Algarve, Portugal. Patrícia Pinto was funded by FCT (grant, SFRH/BPD/ 84033/2012) and researcher contract with the University of Algarve. This study was partially funded by CESAM (UID/AMB/50017-POCI-01-0145-FEDER-007638), to FCT/MCTES through national funds (PIDDAC), and co-funding by FEDER, within the PT2020 Partnership Agreement and FCT/UID/Multi/04326/2019/CCMAR.

\section{Author Contribution Statement}

Natália Marques conceived the experiments, performed the experiments and discussed the results. Alexandra Filipe performed the real-time quantitative PCR experiments. Patrícia Pinto analyzed the quantitative PCR data and discussed the results. Deborah Power gave the technical and scientific support. José Barroso, Helena Trindade and Ana Cristina Figueiredo performed the SPME-GC and SPME GC/MS analysis, gave the scientific and technical support and discussed the results. Natália Marques wrote the manuscript with input from the other authors. All the authors read and approved the final manuscript.

\section{References}

[1] R. Morales, 'The history, botany and taxonomy of the genus Thymus', Taylor \& Francis, London, 2002.

[2] J. Gershenzon, M. Maffei, R. Croteau, 'Biochemical and histochemical localization of monoterpene biosynthesis in the glandular trichomes of spearmint (Mentha spicata)', Plant Physiol. 1989, 89, 1351-1357.

[3] E. Werker, 'Trichome diversity and development', Adv. Bot. Res. 2000, 31, 1-35.
[4] M. D. Mendes, A. C. Figueiredo, M. M. Oliveira, H. Trindade, 'Essential oil production in shoot cultures versus fieldgrown plants of Thymus caespititius', Plant Cell Tissue Organ Cult. 2013, 113, 341-351.

[5] M. Majdi, A. Malekzadeh-Mashhady, A. Maroufi, C. Crocoll, 'Tissue-specific gene-expression patterns of genes associated with thymol/carvacrol biosynthesis in thyme (Thymus vulgaris L.) and their differential changes upon treatment with abiotic elicitors', Plant Physiol. Biochem. 2017, 115, $152-162$.

[6] L. Ascensão, N. Marques, M. S. Pais, 'Glandular trichomes on vegetative and reproductive organs of Leonotis leonurus (Lamiaceae)', Ann. Bot. 1995, 75, 619-626.

[7] K. Xiao, X. Mao, Y. Lin, H. Xu, Y. Zhu, Q. Cai, H. Xie, J. Zhang, 'Trichome, a functional diversity phenotype in plant', Mol. Biol. 2017, 6, 183.

[8] A. Tissier, J. A. Morgan, N. Dudareva, 'Plant volatiles: going 'in' but not 'out' of trichome cavities', Trends Plant Sci. 2017, 22, 930-934.

[9] Z. Yosr, C. Hnia, T. Rim, B. Mohamed, 'Changes in essential oil composition and phenolic fraction in Rosmarinus officinalis L. var. typicus Batt. organs during growth and incidence on the antioxidant activity', Ind. Crops Prod. 2013, 43, 412-419.

[10] C. N. Hassiotis, F. Ntana, D. M. Lazari, S. Poulios, K. E. Vlachonasios, 'Environmental and developmental factors affect essential oil production and quality of Lavandula angustifolia during flowering period', Ind. Crops Prod. 2014, 62, 359-366.

[11] M. Asadollahi-Baboli, A. Aghakhani, V. Bikdeloo, 'Application of polyamide nanofibers, SPME/GC/MS, and chemometrics for comprehensive analysis of volatiles in Thymus vulgaris L. and Thymus serpyllum L', Food Anal. Methods 2016, 9, 528-536.

[12] C. Crocoll, J. Asbach, J. Novak, J. Gershenzon, J. Degenhardt, 'Terpene synthases of oregano (Origanum vulgare L.) and their roles in the pathway and regulation of terpene biosynthesis', Plant Mol. Biol. 2010, 73, 587-603.

[13] Z. A. Demissie, M. A. Cella, L. S. Sarker, T. J. Thompson, M. R. Rheault, S.S. Mahmoud, 'Cloning, functional characterization and genomic organization of 1,8-cineole synthases from Lavandula', Plant Mol. Biol. 2012, 79, 393-411.

[14] M. G. Miguel, F. Duarte, F. Venâncio, R. Tavares, 'Variation in the main components of the essential oils from the leaves and flowers of Portuguese Thymus albicans over a single season', J. Essent. Oil Res. 2004, 16, 169-171.

[15] R. C. S. Sá, L. N. Andrade, D. P. Sousa, 'A review on antiinflammatory activity of monoterpenes', Molecules 2013, $18,1227-1254$.

[16] G. F. R. Caldas, A. R. da Silva Oliveira, A. V. Araújo, S. S. L. Lafayette, G. S. Albuquerque, J. C. Silva-Neto, J. H. CostaSilva, F. Ferreira, J. G. M. da Costa, A. G. Wanderley, 'Gastroprotective mechanisms of the monoterpene 1,8-cineole (Eucalyptol)', PLoS One 2015, 10, e0134558.

[17] M. G. Miguel, A. C. Figueiredo, M. M. Costa, D. Martins, J. Duarte, J. G. Barroso, L. G. Pedro, 'Effect of the volatile constituents isolated from Thymus albicans, T. mastichina T. carnosus and Thymbra capitata in sunflower oil', Food / Nahrung 2003, 47, 397-402.

[18] A. Filipe, J.C. R. Cardoso, M. G. Miguel, L. Anjos, H. Trindade, A. C. Figueiredo, J. Barroso, D. M. Power, N. T. 
Marques, 'Molecular cloning and functional characterization of a monoterpene synthase isolated from the aromatic wild shrub Thymus albicans', J. Plant Physiol. 2017, 218, 3544.

[19] A. C. Figueiredo, J. G. Barroso, L. G. Pedro, L. Salgueiro, M. G. Miguel, M. L. Faleiro, 'Portuguese Thymbra and Thymus species volatiles: chemical composition and biological activities', Curr. Pharm. Des. 2008, 14, 3120-3140.

[20] J. A. T. Silva, A. C. Figueiredo, J. G. Barroso, L. G. Pedro, L. Ascensão, 'Estudo dos tricomas glandulares e do óleo essencial de Thymus mastichina L.', Actas do $1^{\circ}$ Colóquio Nacional de Plantas Aromáticas e Medicinais, Associação Portuguesa de Horticultura 1996, p. 229-232 (in Portuguese).

[21] X. Yu, C. Liang, H. Fang, X. Qi, W. Li, Q. Shang, 'Variation of trichome morphology and essential oil composition of seven Mentha species', Biochem. Syst. Ecol. 2018, 79, 3036.

[22] L. B. Pérez-Estrada, Z. Cano-Santana, K. Oyama, 'Variation in leaf trichomes of Wigandia urens: environmental factors and physiological consequences', Tree Physiol. 2000, 20, 629-632.

[23] A. C. Figueiredo, J. G. Barroso, in 'Medicinal and Aromatic Plants (MAP): How do they adapt to the environment?', Ed. Á. Máthé, Springer, Dordrecht, 2015, p. 87.

[24] M. A. A. Souza, L. A. Santos, D. M. C. Brito, J. F. Rocha, R. N. Castro, M. S. Fernandes, S. R. Souza, 'Influence of light intensity on glandular trichome density, gene expression and essential oil of menthol mint (Mentha arvensis L.)', J. Essent. Oil Res. 2016, 28, 138-145.

[25] L. R. S. Tozin, M. M. O. Marques, T. M. Rodrigues, 'Glandular trichome density and essential oil composition in leaves and inflorescences of Lippia origanoides Kunth (Verbenaceae) in the Brazilian Cerrado', An. Acad. Bras. Cienc. 2015, $87,943-953$.

[26] S. Song, M. Gu, F. Chen, 'Analysis on volatile components of flowers and leaves of Thymus mongolicus by SPME-GC/ MS', Med. Plant 2018, 9, 8-10.

[27] R. Rios-Estepa, I. Lange, J. M. Lee, B. M. Lange, 'Mathematical modeling-guided evaluation of biochemical, develop- mental, environmental, and genotypic determinants of essential oil composition and yield in peppermint leaves', Plant Physiol. 2010, 152, 2105-2119.

[28] G. W. Turner, E. M. Davis, R. B. Croteau, 'Immunocytochemical localization of short-chain family reductases involved in menthol biosynthesis in peppermint', Planta 2012, 235, 1185-1195.

[29] C. Liu, N. Srividya, A. N. Parrish, W. Yue, M. Shan, Q. Wu, B. M. Lange, 'Morphology of glandular trichomes of Japanese catnip (Schizonepeta tenuifolia Briquet) and developmental dynamics of their secretory activity', Phytochemistry 2018, 150, 23-30.

[30] A. Fähnrich, A. Brosemann, L. Teske, M. Neumann, B. Piechulla, 'Synthesis of 'cineole cassette' monoterpenes in Nicotiana section Alatae: gene isolation, expression, functional characterization and phylogenetic analysis', Plant Mol. Biol. 2012, 79, 537-553.

[31] M. L. Wise, T. J. Savage, E. Katahira, R. Croteau, 'Monoterpene synthases from common sage (Salvia officinalis)', J. Biol. Chem. 1998, 273, $14891-14899$.

[32] A. Lane, A. Boecklemann, G. Woronuk, L. Sarker, S. Mahmoud, 'A genomics resource for investigating regulation of essential oil production in Lavandula angustifolia', Planta 2010, 231, 835-845.

[33] A. C. Figueiredo, M. S. Pais, 'Ultrastructural aspects of the glandular cells from the secretory trichomes and from the cell suspension cultures of Achillea millefolium L. ssp. Millefolium', Ann. Bot. 1994, 74, 179-190.

[34] C. A. Schneider, W. S. Rasband, K. W. Eliceiri, 'NIH Image to ImageJ: 25 years of image analysis', Nat. Methods 2012, 9, 671-675.

[35] A. M. Afonso, R. Guerra, A. M. Cavaco, P. Pinto, A. Andrade, A. Duarte, D. M. Power, N. T. Marques, 'Identification of asymptomatic plants infected with Citrus tristeza virus from a time series of leaf spectral characteristics', Comput. Electron. Agric. 2017, 141, 340-350.

Received November 25, 2019 Accepted January 23, 2020 